\title{
Acetylcholine-Induced Coronary Vasoconstriction and Negative Inotropy in the Neonatal Pig Heart
}

\author{
ROBERT J. ASCUITTO, NANCY T. ROSS-ASCUITTO, DAVID RAMAGE, \\ KATHLEEN H. MCDONOUGH, AND PHILIP J. KADOWITZ \\ Department of Pediatrics, Section of Cardiology [R.J.A., N.T.R-A., D.R.] and Department of Pharmacology \\ [P.J.K.], Tulane University School of Medicine, and Department of Physiology [K.H.M.], Louisiana State \\ University School of Medicine, New Orleans, Louisiana 70112
}

\begin{abstract}
We investigated the influence of exogenously administered acetylcholine, nitric oxide, ADP, ATP, bradykinin, and substance $P$ on coronary vascular tone in isolated, neonatal pig hearts $(\leq 4 \mathrm{~d})$. Paced $(180 \mathrm{bpm})$, isovolumically beating hearts underwent retrograde aortic perfusion, with an erythrocyte-enriched solution (hematocrit $0.15-0.20)$ at constant coronary flow $(\approx 2.5 \mathrm{~mL} / \mathrm{min} / \mathrm{g})$ corresponding to a perfusion pressure of $\approx 60 \mathrm{~mm} \mathrm{Hg}$. Agonists were injected into the aortic root, and the peak change in coronary perfusion pressure from baseline and left ventricular pressure development were assessed. Nitric oxide (3 $\mu \mathrm{L})$, ADP (30 nmol), ATP (30 nmol), bradykinin $(125 \mathrm{ng})$, and substance $P(50 \mathrm{ng})$ decreased the perfusion pressure (vasodilatation) by $16.9 \pm 1.2,25.3 \pm 4.4,18.3$ $\pm 1.2,18.9 \pm 1.4$, and $7.1 \pm 1.6 \mathrm{~mm} \mathrm{Hg}$, respectively. Acetylcholine $(0.5$ and $1.0 \mathrm{nmol})$ produced a modest decrease in perfusion pressure (vasodilatation) of $4.2 \pm 0.8$ and $3.8 \pm 0.5 \mathrm{~mm} \mathrm{Hg}$, respectively, whereas acetylcholine $(5,20$, and $100 \mathrm{nmol})$ increased the perfusion pressure (vasoconstriction) by $16.7 \pm 2.7,48.2 \pm 8.2$, and $85.3 \pm$ $15.1 \mathrm{~mm} \mathrm{Hg}$, respectively. Acetylcholine also decreased left ventricular peak systolic pressure from $108.7 \pm 5.0$ to $69.2 \pm 4.6,56.3 \pm 6.1$, and $48.2 \pm 6.4 \mathrm{~mm} \mathrm{Hg}$, for the 5 , 20 , and $100 \mathrm{nmol}$ doses, respectively. Responses to acetylcholine were abolished by atropine $(50 \mathrm{nmol})$. In a separate group of hearts, indomethacin $\left(10^{-6} \mathrm{M}\right)$ reduced the peak change in perfusion pressure for the 5,20 , and $100 \mathrm{nmol}$ doses of acetylcholine by $87 \%, 66 \%$, and $48 \%$, respectively. In other hearts, the calcium channel antagonist, nisoldipine $\left(10^{-7} \mathrm{M}\right)$, reduced the peak change in perfusion pressure for the 5, 20, and $100 \mathrm{nmol}$ doses of acetylcholine by $87 \%$, $77 \%$, and $\mathbf{5 6 \%}$, respectively. In summary, acetylcholine causes predominantly coronary vasoconstrictive and negative inotropic effects in neonatal pig hearts; both actions are muscarinic receptor mediated. Our data also indicate that a cyclooxygenase product may, in part, be involved in this vasoconstriction, and that an extracellular source of calcium contributes to the vasoconstrictive process. (Pediatr Res 32: 236-242, 1992)
\end{abstract}

\section{Abbreviations}

ACh, acetylcholine

EDRF, endothelium-derived relaxing factor

BK, bradykinin

sub $P$, substance $P$

NO, nitric oxide

Received October 2, 1991; accepted March 18, 1992.

Correspondence: Robert J. Ascuitto, M.D., Ph.D., Tulane University Medical Center, Department of Pediatrics, 1430 Tulane Ave., New Orleans, LA 70122.

Supported by a grant from the Louisiana Board of Regents, LEQSF 1989-91RD-A-16.
PSP, peak systolic pressure

$\mathrm{dP} / \mathrm{dt}$, change in pressure per unit time

Some 30 years ago, Cassin et al. (1) showed that ACh dilates the normally high tone pulmonary vasculature of the fetus. More recently, ACh has been shown to be a potent dilator of precontracted, isolated systemic and pulmonary arteries from neonates of several species (2). As originally demonstrated by Furchgott and Zawadzki (3), the vasorelaxation produced by ACh requires the presence of a functionally intact endothelium and involves the production of an EDRF. ACh has also been shown to relax precontracted, epicardial coronary arteries isolated from several species, most notably the dog (4). It has become apparent, however, that these results cannot be generalized to all mammals, because large coronary arteries of adult pigs (5) and humans (6, 7) can constrict in vitro to exogenously administered ACh. Recently, Cowan and McKenzie (8) demonstrated that ACh reduces myocardial blood flow when injected into the left anterior descending coronary artery of in vivo adult pig hearts. Although this finding is consistent with the vasoconstrictor responses observed with $\mathrm{ACh}$ using isolated coronary arteries, the coronary vascular effects of $\mathrm{ACh}$ in intact, functioning hearts require additional investigation. Such information is of importance, because cholinergic mechanisms may play a role in the regulation of coronary blood flow. Moreover, little, if anything, is known about the actions of $\mathrm{ACh}$ on the coronary vasculature of the immature heart.

Therefore, the purpose of the present investigation was to study the effects of $\mathrm{ACh}$ on mechanical function and coronary vascular tone, using neonatal pig hearts. Isolated, isovolumically beating hearts were perfused with an erythrocyte-enriched solution under conditions of constant coronary flow. The effects of NO, ADP, ATP, BK, and sub $\mathrm{P}$ on the coronary vasculature were also examined. NO, which is believed to be EDRF, was studied as an example of a direct smooth muscle vasodilator (9). The remaining agents were investigated because they produce endothelial-dependent coronary vasodilatation in mature hearts (10). We hypothesized that ACh would cause coronary vasoconstriction in neonatal pig hearts, and that this vasoconstriction would be inhibited by indomethacin, because $\mathrm{ACh}$ has also been shown to produce cerebrovascular constriction in piglets, which is mediated by the release of cyclooxygenase products (11).

\section{MATERIALS AND METHODS}

Preparation of erythrocytes and perfusate. The perfusate $\left(37^{\circ} \mathrm{C}\right)$ consisted of a crystalloid solution containing: $200 \mu \mathrm{U} / \mathrm{mL}$ insulin, $118 \mathrm{mM} \mathrm{NaCl}, 4.7 \mathrm{mM} \mathrm{KCl}, 2.4 \mathrm{mM} \mathrm{MgSO}_{4}, 1.2 \mathrm{mM}$ $\mathrm{KH}_{2} \mathrm{PO}_{4}, 25 \mathrm{mM} \mathrm{NaHCO}, 2.4 \mathrm{mM} \mathrm{CaCl}_{2}, 5.5 \mathrm{mM}$ glucose, 2- 
$4 \mathrm{mM}$ lactate, and 2\% BSA (Cohn Fraction V; U.S. Biochemical Corp., Cleveland, OH). Outdated, saline-washed, human erythrocytes (tested negative for hepatitis $B$ and human immunodeficiency virus) were then suspended in this solution (hematocrits $0.15-0.20$ ) to provide adequate oxygen delivery and buffering capacity for these large hearts $(12.6 \pm 1.3 \mathrm{~g})$. The $\mathrm{pH}$ of the final solution was adjusted to 7.4-7.45 by titration with $1 \mathrm{~N} \mathrm{NaOH}$.

Preparation of solutions. Indomethacin (Sigma Chemical Co., St. Louis, MO) was dissolved in warm $\mathrm{NaCO}_{3}(0.08 \%)$ and protected from light. An aliquot of this solution was added to the perfusate to yield an indomethacin concentration of $10^{-6} \mathrm{M}$. Nisoldipine (Miles Inc., Dallas, TX) was dissolved in Cremophor EL (Sigma), Tris, and Tris- $\mathrm{HCl}(\mathrm{pH} 7.4)$. The resulting suspension was warmed, and $2 \mathrm{~mL}$ of polyethylene glycol and $10 \mathrm{~mL}$ of Tris $(\mathrm{pH}$ 7.4) were added. This stock solution was stored frozen and protected from light. When required, this solution was thawed, diluted with saline, and infused into the aortic root at a rate equivalent to a perfusate nisoldipine concentration of $10^{-7}$ M. ACh (Sigma), ADP, and ATP (Boehringer Mannheim, Indianapolis, IN) were dissolved in saline and prepared on the day of an experiment. BK (Sigma) and sub P (Sigma) were also dissolved in saline and frozen $\left(\approx-10^{\circ} \mathrm{C}\right)$ in bottles protected from light. Stock solutions were thawed for each experiment and diluted in saline when necessary. NO was dissolved in reagent grade methanol under $\mathrm{O}_{2}$-free conditions. The precise concentration of NO in the solution was unknown, although it was estimated to be 1-2 mM. Thus, only the volume of the NO solution injected is specified. Atropine sulfate (Abbott Laboratories, Chicago, IL) was dissolved in perfusate solution and injected as a bolus into the aortic root.

Preparation of isolated hearts. Pigs, $12 \mathrm{~h}$ to $4 \mathrm{~d}$ of age, were used for these studies. Isolated, isovolumically beating hearts were prepared as described previously $(12,13)$. Briefly, piglets were anesthetized with sodium pentobarbital (Nembutal, $25 \mathrm{mg}$ / $\mathrm{kg}$ intraperitoneally; Abbott), anticoagulated with sodium heparin (heparin, $1000 \mathrm{U}$ i.v.), and mechanically ventilated via a tracheostomy. After a sternotomy, the hearts were excised rapidly and immediately placed in ice-cold, Krebs-Henseleit solution.

Using the modified Langendorff system described previously $(12,13)$ and depicted in Figure 1 , nonrecirculating, retrogradeaortic perfusion was initiated with the crystalloid solution for $\approx 5$ min (to flush the coronary arteries of debris), and then continued with the erythrocyte-enriched solution. Hearts were allowed to equilibrate while being perfused for $\approx 15 \mathrm{~min}$ at constant coronary perfusion pressure. The enhanced oxygen-carrying capacity provided by the erythrocytes ensured that coronary flow rates could be kept in the physiologic range (14) without compromising mechanical function. Furthermore, coronary vascular tone would be maintained and coronary vasodilator responses could be elicited during the course of an experiment. We have demonstrated previously for example, that these piglet hearts exhibit hyperemic responses after ischemia (12) and that coronary vascular resistance can decrease $\approx 3$-fold with hypoxia (13). Thus, the coronary vascular reserve was adequate, and responses to agonists could be studied without the necessity, and additional complexity, of using agents to increase or decrease coronary vascular tone. Such agents might also adversely affect mechanical function.

After equilibration, hearts were then perfused at constant coronary flow $(\approx 2.5 \mathrm{~mL} / \mathrm{min} / \mathrm{g}$ wet heart wt) that was chosen to produce a coronary perfusion pressure of $\approx 60 \mathrm{~mm} \mathrm{Hg}$. Perfusing hearts at constant coronary flow allowed us to study vasoconstrictor responses without impairing oxygen delivery, which may have compromised mechanical function. Also, because coronary flow was held constant, changes in coronary perfusion pressure reflected alterations in coronary vascular tone. In this preparation, coronary venous return egressed from the pulmonary artery cannula, from which coronary flow was measured. Left ventricular mechanical function was assessed by isovolumic systolic pressure and the maximum rate of change of systolic pressure

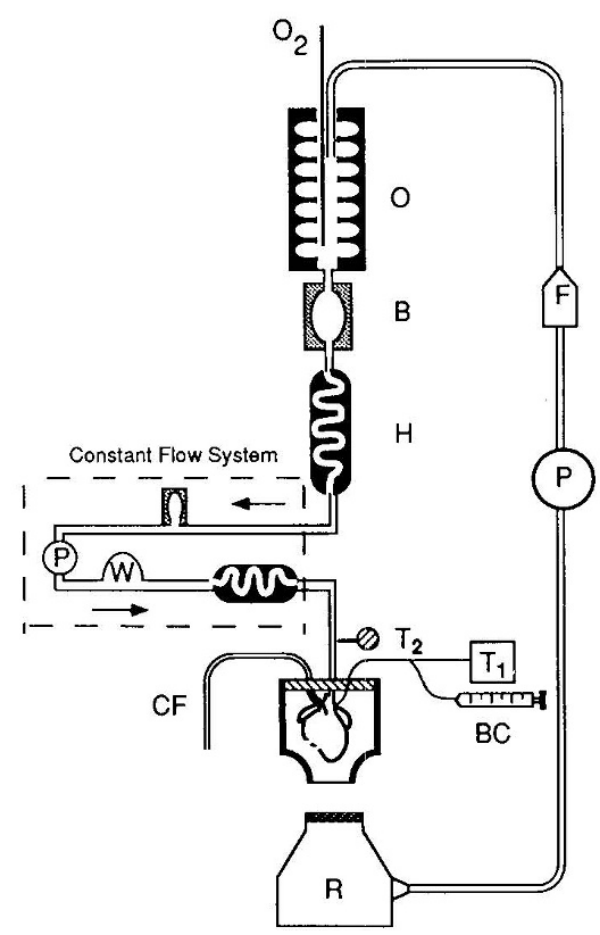

Fig. 1. Perfusate in reservoir $(R)$ was pumped through an oxygenating column $(O)$, bubble trap $(B)$, and heating condenser $(H)$. Before entering the aorta, the perfusate passed through a constant-flow system containing a pump $(P)$ and a pulsatile flow-damping chamber $(W)$, which maintained the coronary flow at the desired constant value. Myocardial temperature was kept at $37^{\circ} \mathrm{C}$ by enclosing the heart in a heated water jacket. Left ventricular isovolumic pressure was monitored by a pressure transducer $\left(T_{1}\right)$ attached to a fluid-filled balloon catheter $(B C)$ in the left ventricular chamber. Coronary perfusion pressure was monitored with a pressure transducer $\left(T_{2}\right)$ attached to a side port above the heart. Coronary venous return egressed from the pulmonary artery cannula $(C F)$. Coronary venous return was collected separately and not returned to the reservoir $(R)$.

with respect to time $(\mathrm{dP} / \mathrm{dt})$, which were monitored via a fluidfilled balloon catheter in the ventricular chamber. The left ventricular end diastolic pressure was adjusted by changing the volume of fluid in the balloon. The end diastolic pressure was set at 2--4 $\mathrm{mm} \mathrm{Hg}$, which is normal for a neonate. Hearts were paced via the right ventricle at $180 \mathrm{bpm}$, so that ventricular contractions could be maintained at a constant rate when studying agents $(\mathrm{ACh})$ that affect atrioventricular conduction. The arterial perfusate oxygen content was maintained at $\approx 7.5-8.0$ vol\% $\left[\mathrm{PO}_{2} \approx 250-300\right.$ torr $\left.(33.3-40 \mathrm{kPa})\right]$ by passing a mixture of $95 \% \mathrm{O}_{2}$ and $5 \% \mathrm{CO}_{2}$ through the perfusate in the Langendorff column.

Experimental protocols. The first part of this study was designed to test whether ACh produces coronary vasoconstriction in neonatal pig hearts. Hearts $(n=5)$ underwent retrograde aortic perfusion at constant coronary flow. The agonists ACh (5, 20 , and $100 \mathrm{nmol}), \mathrm{ADP}(30 \mathrm{nmol}), \mathrm{BK}(125 \mathrm{ng})$, and sub P (50 ng) were injected as a bolus, over an $\approx 1$-s period, into the aortic root of hearts in a random sequence. The resulting changes in coronary perfusion pressure from baseline (i.e. just before the administration of each agonist) were then determined. Changes in perfusion pressure were expressed in $\mathrm{mm} \mathrm{Hg}$. Agonists were administered only after perfusion pressure had stabilized. Based on preliminary studies, the doses of agonists were selected so that vascular tone would return to near control levels upon washout of the agonist. These doses were also found to be similar to those used in previous vascular studies $(10,15-18)$. In additional hearts, NO ( $3 \mu \mathrm{L} ; n=5)$ and ATP (30 nmol; $n=5)$ were studied in a similar fashion. These experiments were performed to verify 
that the coronary vasculature of these isolated hearts responded to a direct smooth muscle vasodilator $(\mathrm{NO})$ in conjunction with an endothelial dependent vasodilator (ATP).

The second part of this investigation was designed to determine whether the release of a cyclooxygenase product mediates the vasoconstrictive effect of $\mathrm{ACh}$. The three doses of $\mathrm{ACh}$ were administered to five additional hearts in amounts of 5, 20, and $100 \mathrm{nmol}$, and the corresponding changes in perfusion pressure were determined. Alterations in left ventricular mechanical function in response to ACh were also assessed. After baseline measurements, hearts were perfused for an additional $30 \mathrm{~min}$ with perfusate supplemented with indomethacin $\left(10^{-6} \mathrm{M}\right)$. Hearts were then rechallenged with $\mathrm{ACh}$ in the presence of indomethacin. This concentration of indomethacin has routinely been used by other investigators in studies of vascular responses to arachidonic acid, ACh, and BK $(2,15)$. The peak changes in perfusion pressure in response to $\mathrm{ACh}$, in the presence of indomethacin, were compared with the corresponding changes in perfusion pressure obtained with the same doses of $\mathrm{ACh}$, but before the addition of indomethacin. The peak changes in perfusion pressure in response to the doses of $\mathrm{ACh}$, in the presence of indomethacin, were also compared with corresponding changes in perfusion pressure obtained in four control hearts perfused for the same period of time but without the addition of indomethacin. Because indomethacin was found to increase perfusion pressure and, thus, vascular tone, $\mathrm{ACh}$ was also studied in three additional hearts in which the vasoconstricting thromboxane analogue U46619 was injected as a bolus into the aortic root before the administration of ACh. On average, $10 \mathrm{ng}$ of U46619 was found to increase coronary perfusion pressure $\approx 5 \mathrm{~mm} \mathrm{Hg}$. We chose a dose of U46619 so as to increase perfusion pressure $\approx 25 \mathrm{~mm} \mathrm{Hg}$, the increase in perfusion pressure found with indomethacin (see Results). Thus, these experiments served as an additional control for the indomethacin studies and also allowed us to investigate whether an increased vascular tone unmasked a vasodilation from ACh.

The third part of this study examined whether the vasoconstriction caused by $\mathrm{ACh}$ involved an extracellular source of calcium. ACh was administered to five additional hearts, and the changes in perfusion pressure were determined. After baseline measurements, hearts were perfused for an additional $20 \mathrm{~min}$ with the dihydropyridine calcium antagonist, nisoldipine, which was infused into the aortic root at a rate equivalent to a perfusate concentration of $10^{-7} \mathrm{M}$. Hearts were then rechallenged with $\mathrm{ACh}$ in the presence of nisoldipine. This concentration of nisoldipine has been shown to inhibit ACh-induced contractions of adult pig epicardial coronary artery strips (19). The peak changes in perfusion pressure in response to $\mathrm{ACh}$, in the presence of nisoldipine, were compared with the corresponding changes in perfusion pressure obtained before the addition of nisoldipine.

Data analysis. The results are presented as mean \pm SEM. Analysis of variance with repeated measures followed by the Student-Newmann-Keuls comparison procedure was used to analyze differences in the response to $\mathrm{ACh}$ or other agonists. Differences among means were considered to be significant when $p<0.05$.

\section{RESULTS}

Influence of $A C h$ and agonists on coronary perfusion pressure. The peak change in coronary perfusion pressure, in response to each vasoactive agonist, is shown in Figure 2 . In these experiments, coronary flow was $2.6 \pm 0.3 \mathrm{~mL} / \mathrm{min} / \mathrm{g}$, which corresponded to the coronary perfusion pressures shown in Table 1. NO, ADP, ATP, BK, and sub $P$, as expected, decreased perfusion pressure, indicating coronary vasodilatation. In contrast, $\mathrm{ACh}$ produced dose-dependent increases in perfusion pressure, signifying vasoconstriction. The vasoconstrictive response to ACh was abolished by pretreatment with bolus injections into the aortic root of the muscarinic receptor antagonist, atropine (50

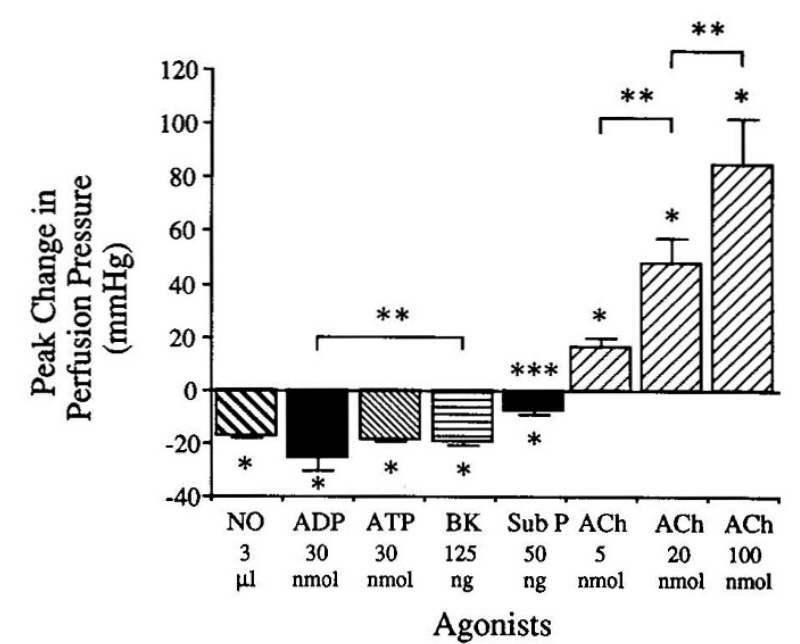

Fig. 2. Peak change in coronary perfusion pressure, expressed in $\mathrm{mm}$ $\mathrm{Hg}$, in response to the agonists NO $(3 \mu \mathrm{L}), \operatorname{ADP}(30 \mathrm{nmol}), \operatorname{ATP}(30$ $\mathrm{nmol})$, BK (125 ng), sub P (50 ng), and ACh (5, 20, and $100 \mathrm{nmol})$. The results are expressed as mean \pm SEM in all figures. Asterisks indicate statistically significant differences from baseline coronary perfusion pressure, i.e. perfusion pressure just before the addition of each agonist. Asterisks above the horizontal lines indicate statistically significant differences between the groups joined by the lines. ${ }^{* * *}$, the response to sub $\mathrm{P}$ is statistically different when compared with NO, ADP, ATP, and BK.

Table 1. Coronary perfusion pressures before administration of agonists

\begin{tabular}{lcc}
\hline Agonist & Dose & Perfusion pressure* \\
\hline NO & $3 \mu \mathrm{L}$ & $61.6 \pm 2.5$ \\
ADP & $30 \mathrm{nmol}$ & $60.5 \pm 3.0$ \\
ATP & $30 \mathrm{nmol}$ & $63.3 \pm 3.4$ \\
BK & $125 \mathrm{ng}$ & $58.1 \pm 1.6$ \\
Sub P & $50 \mathrm{ng}$ & $56.3 \pm 6.3$ \\
ACh & $5 \mathrm{nmol}$ & $50.5 \pm 3.8$ \\
ACh & $20 \mathrm{nmol}$ & $53.5 \pm 3.5$ \\
ACh & $100 \mathrm{nmol}$ & $56.0 \pm 2.7$ \\
\hline
\end{tabular}

* Baseline coronary perfusion pressures $(\mathrm{mm} \mathrm{Hg})$, mean $\pm \mathrm{SEM}$, immediately before the administration of the agonists indicated.

nmol). The bolus administration of atropine itself had no effect on perfusion pressure or mechanical function.

Influence of $A C h$ on mechanical function. Under baseline conditions, ACh produced dose-dependent increases in coronary perfusion pressure and decreases in left ventricular PSP, as shown in Figure 3. The negative inotropic effect was also abolished by pretreatment with atropine. Figure 4 shows a typical tracing for perfusion pressure, left ventricular pressure, and $\mathrm{dP} / \mathrm{dt}$ in response to $20 \mathrm{nmol}$ of $\mathrm{ACh}$. Upon administration of $\mathrm{ACh}$, there was a dramatic increase in perfusion pressure and a reduction in left ventricular systolic pressure and $\mathrm{dP} / \mathrm{dt}$. Similar effects on left ventricular pressure were found for the 5- and 100-nmol doses of $\mathrm{ACh}$. The duration of action of $\mathrm{ACh}$ was short $(\approx 1 \mathrm{~min})$, and there was a rebound in left ventricular systolic pressure and a slight decrease in perfusion pressure, below baseline (vasodilatation), after washout of ACh. NO, ADP, ATP, BK, and sub P were found to produce only minor decreases in left ventricular $\mathrm{PSP}$, averaging $\approx 5 \mathrm{~mm} \mathrm{Hg}$ (data not shown).

Influence of indomethacin on responses to ACh. In these experiments, coronary flow was $2.3 \pm 0.1 \mathrm{~mL} / \mathrm{min} / \mathrm{g}$. The cyclooxygenase inhibitor, indomethacin $\left(10^{-6} \mathrm{M}\right)$, increased the baseline coronary perfusion pressure by $24 \pm 7 \mathrm{~mm} \mathrm{Hg}$ in three hearts, whereas in the other two hearts perfusion pressure increased transiently. Indomethacin also reduced the peak change in perfusion pressure for the 5-, 20-, and 100-nmol doses of ACh by $87 \%, 66 \%$, and $48 \%$, respectively (Fig. 5). Indomethacin was 

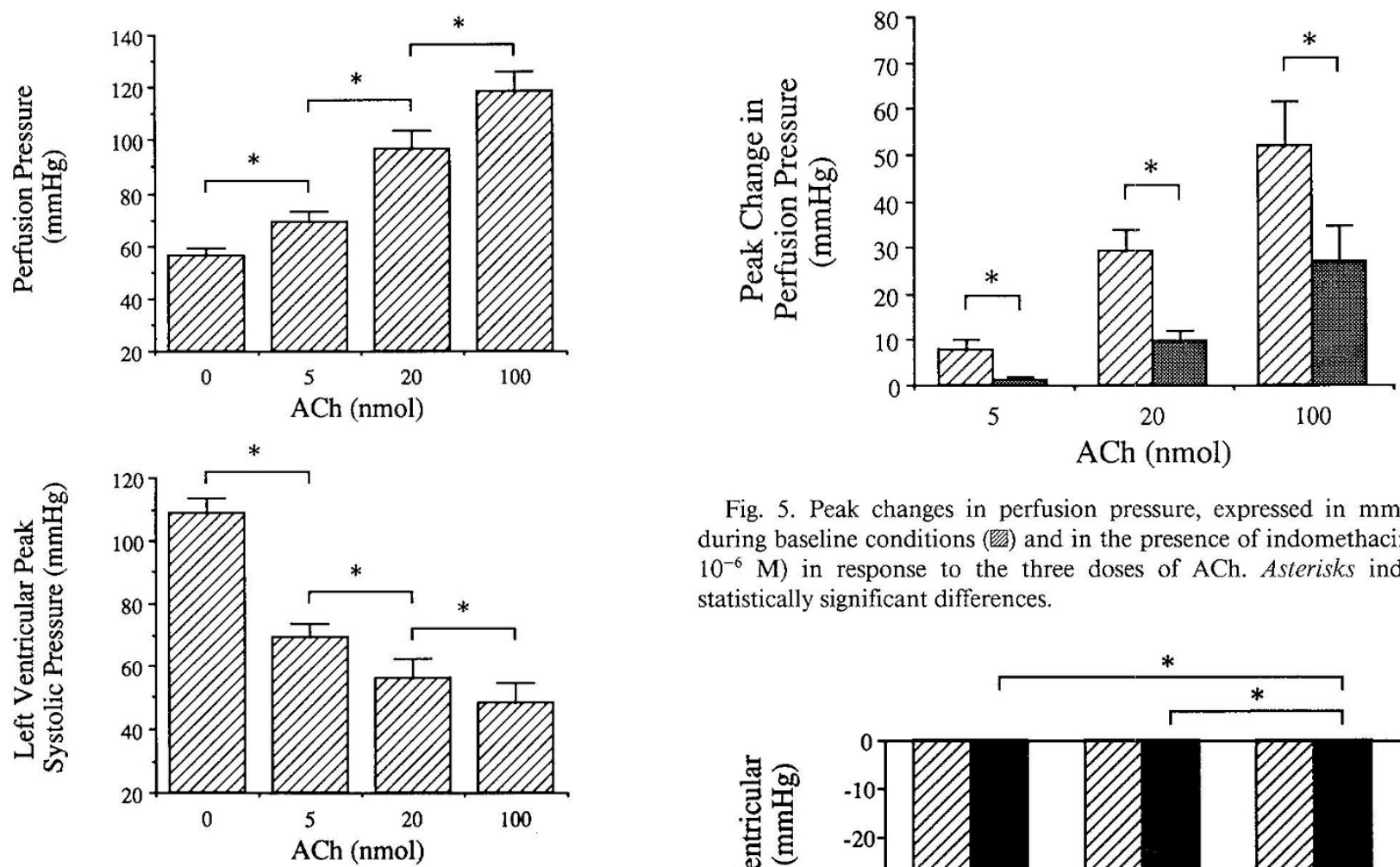

Fig. 5. Peak changes in perfusion pressure, expressed in $\mathrm{mm} \mathrm{Hg}$,

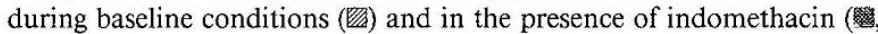
$10^{-6} \mathrm{M}$ ) in response to the three doses of ACh. Asterisks indicate statistically significant differences.

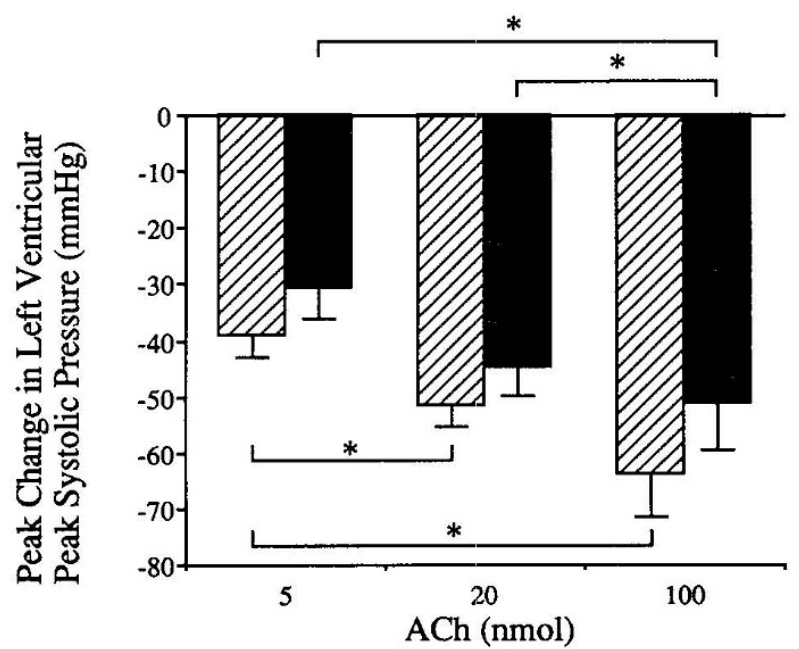

Fig. 6. Peak changes in left ventricular PSP, expressed in $\mathrm{mm} \mathrm{Hg}$, in response to the three doses of $\mathrm{ACh}(\mathbb{Z})$ and to the three doses of $\mathrm{ACh}$ administered in the presence of indomethacin $\left(\mathbf{\square}, 10^{-6} \mathrm{M}\right)$. Asterisks indicate statistically significant differences as described above.

also found to reduce the magnitude of the decrease in left ventricular PSP, produced by the 5-, 20-, and 100-nmol doses of ACh, on average by $\approx 22 \%, \approx 13 \%$, and $\approx 20 \%$, respectively (Fig. 6 ). The baseline PSP, before the administration of ACh and the addition of indomethacin, was $103.3 \pm 4.0 \mathrm{~mm} \mathrm{Hg}$; the PSP, when measured $\approx 44$ min later, before rechallenging with $\mathrm{ACh}$ and still in the presence of indomethacin, was $99.5 \pm 4.4 \mathrm{~mm}$ $\mathrm{Hg}$. These results indicate that, although indomethacin had little effect on PSP, indomethacin still had a significant effect on perfusion pressure. In four control hearts, perfused for an equivalent period of time but without the addition of indomethacin, there was no substantial decrease over time in the vasoconstrictor response to $\mathrm{ACh}$ (Fig. 7). In these control hearts, the baseline PSP, before the administration of $\mathrm{ACh}$, was $101.3 \pm 1.3 \mathrm{~mm} \mathrm{Hg}$; the PSP when measured $\approx 42$ min later, before rechallenging with $\mathrm{ACh}$, was $96.7 \pm 1.7 \mathrm{~mm} \mathrm{Hg}$.

The influence of increasing coronary perfusion pressure with $\mathrm{U} 46619$ on the responses to $\mathrm{ACh}$ is shown in Figure 8. At elevated tone, the vasoconstrictive response to $\mathrm{ACh}$ was slightly attenuated, although this effect is not statistically significant. Furthermore, when one compares the responses to ACh in the presence of indomethacin (Fig. 5) to those in the presence of U46619 (Fig. 8), it can be seen that indomethacin's attenuation of ACh's vasoconstrictive response is not due simply to indomethacin's effect on vascular tone. In these experiments, we also

Fig. 4. An example of a tracing illustrating the responses with respect to time to a $20-\mathrm{nmol}$ dose of ACh. Perfusion pressure (top) and left ventricular pressure (middle) are expressed in $\mathrm{mm} \mathrm{Hg}$; $\mathrm{dP} / \mathrm{dt}$ (bottom) is expressed in $\mathrm{mm} \mathrm{Hg} / \mathrm{s}$. The arrow indicates when $\mathrm{ACh}$ was administered. 


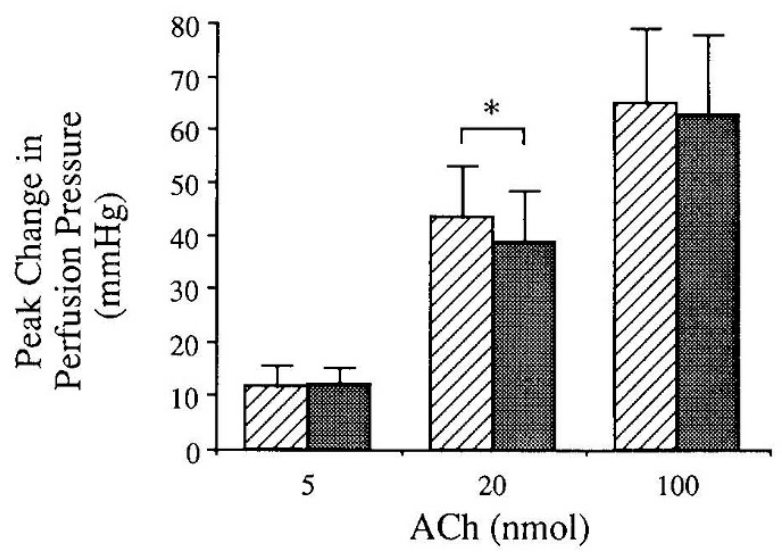

Fig. 7. Peak changes in perfusion pressure, in $\mathrm{mm} \mathrm{Hg}$, in control hearts during baseline conditions ( $(\mathbb{Z})$ and after an additional $\approx 45 \mathrm{~min}$ of perfusion (ilil) in response to the three doses of ACh. For the 20-nmol dose of $\mathrm{ACh}$, there was a statistically significant difference (asterisk) in the peak change in perfusion pressure over time; however, this decrease in perfusion pressure was inconsequential when compared with the decrease observed with indomethacin (see Fig. 5).

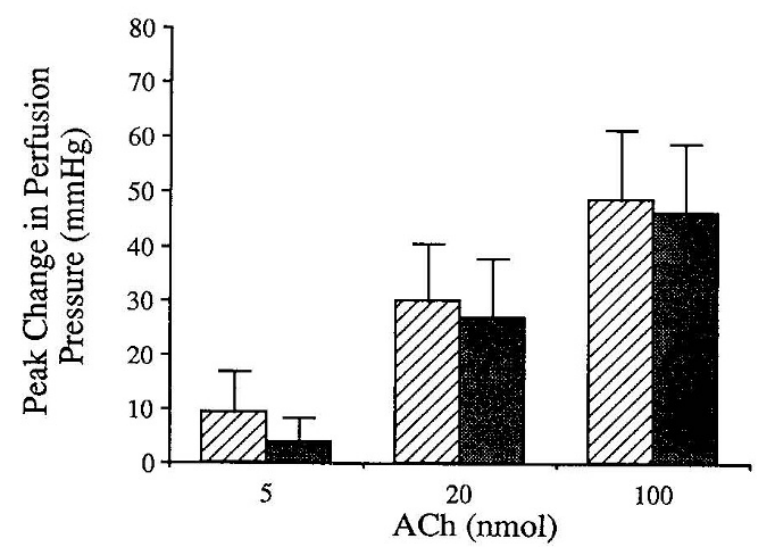

Fig. 8. Peak changes in perfusion pressure, expressed in $\mathrm{mm} \mathrm{Hg}$, during baseline conditions (שי and in the presence of U46619 in response to the three doses of $\mathrm{ACh}$. No statistically significant differences were found.

found that the coronary vasoconstriction produced by U46619 can result in a small transient decrease in PSP. On average, a single bolus of U46619 that increases perfusion pressure $\approx 25$ $\mathrm{mm} \mathrm{Hg}$ resulted in an $\approx 7 \mathrm{~mm} \mathrm{Hg}$ decrease in PSP.

Influence of nisoldipine on vasoconstrictor responses to ACh. In these experiments, coronary flow was $2.9 \pm 0.2 \mathrm{~mL} / \mathrm{min} / \mathrm{g}$. The dihydropyridine calcium antagonist, nisoldipine $\left(10^{-7} \mathrm{M}\right)$, decreased the baseline coronary perfusion pressure by $16 \pm 4$ $\mathrm{mm} \mathrm{Hg}$. Nisoldipine also reduced the peak change in perfusion pressure for the 5-, 20-, and 100-nmol doses of ACh by $87 \%$, $77 \%$, and $56 \%$, respectively (Fig. 9).

Influence of age on vasoconstrictor responses to $A C h$. Our experiments also suggest that there may be a maturational change in the vasoconstrictor response to $\mathrm{ACh}$, because hearts from older animals showed greater vasoconstrictor responses. Table 2 illustrates this by comparing the peak changes in perfusion pressure, in response to $\mathrm{ACh}$, for hearts from the two youngest $(12-36 \mathrm{~h})$ and the two oldest $(72-96 \mathrm{~h})$ pigs. Furthermore, if the dose of ACh was administered on the basis of heart weight, the blunted vasoconstrictive response in the younger hearts would become even more pronounced.

Vasodilator responses to $A C h$. In nine of the 19 experiments, ACh was observed to cause a slight decrease in perfusion pressure $(\approx 1.5 \mathrm{~mm} \mathrm{Hg})$, before the increase in perfusion pressure. This effect was most evident at the 5-nmol dose, and was more

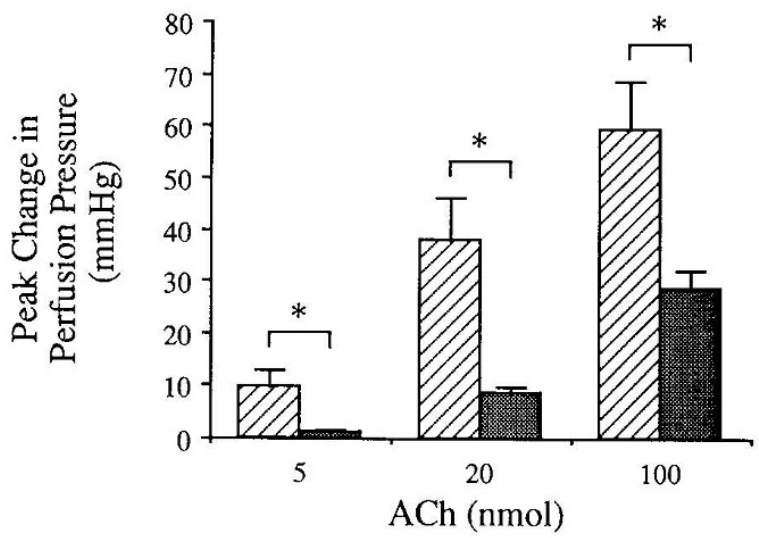

Fig. 9. Peak changes in perfusion pressure, expressed in $\mathrm{mm} \mathrm{Hg}$, during baseline conditions (שृ) and in the presence of nisoldipine (圈, $10^{-6} \mathrm{M}$ ) in response to the three doses of ACh. Asterisks indicate statistically significant differences.

Table 2. Response in perfusion pressure to ACh in youngest and oldest piglets*

\begin{tabular}{lrrrr}
\hline & \multicolumn{2}{c}{$\begin{array}{c}\text { Youngest } \\
\text { piglets } \\
(n=2)\end{array}$} & \multicolumn{2}{c}{$\begin{array}{c}\text { Oldest } \\
\text { piglets } \\
(n=2)\end{array}$} \\
\hline Heart wt (g) & 7.4 & 10.7 & 15.7 & 23.8 \\
Change in PP, & 15.0 & 10.5 & 20.0 & 20.0 \\
$\quad 5 \mathrm{nmol}$ ACh & & & & \\
$\begin{array}{c}\text { Change in PP, } \\
\text { 20 nmol ACh }\end{array}$ & 27.0 & 28.8 & 61.3 & 58.8 \\
$\begin{array}{c}\text { Change in PP, } \\
\text { 100 nmol ACh }\end{array}$ & 35.0 & 40.0 & 101.3 & 120.0 \\
\hline
\end{tabular}

* Comparison of peak change in coronary perfusion pressure (PP, mm $\mathrm{Hg}$ ) to $\mathrm{ACh}$ between youngest (12-36 h) and oldest (72-96 h) piglets.
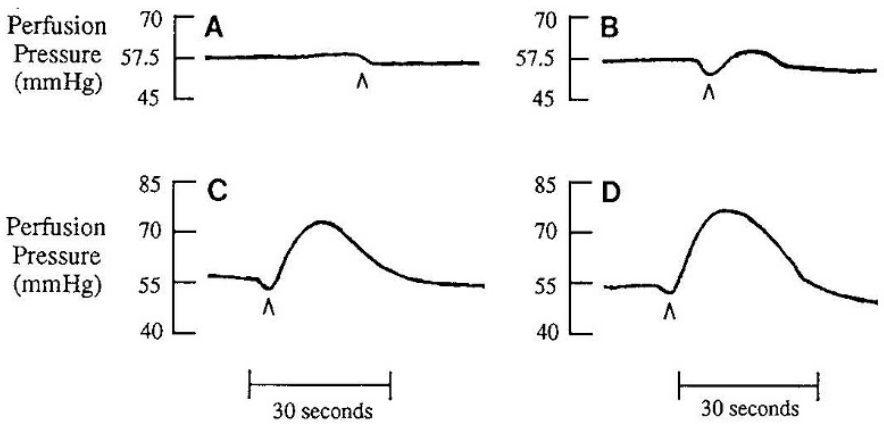

Fig. 10. An example of a tracing illustrating the change in perfusion pressure, expressed in $\mathrm{mm} \mathrm{Hg}$, with respect to time to 1 -nmol $(A) 5$ $\mathrm{nmol}(B) 20-\mathrm{nmol}(C)$, and $100-\mathrm{nmol}(D)$ doses of ACh. Arrow indicates the vasodilatory response within several seconds after administration of ACh.

pronounced for hearts from the youngest animals (Fig. 10). We verified that the decrease in perfusion pressure was not simply related to the vehicle or the mode of delivery of ACh. This observation prompted us to study the effects of lower doses of $\mathrm{ACh}$, i.e. 0.5 and $1.0 \mathrm{nmol}$. ACh reduced perfusion pressure from $62.1 \pm 1.1$ to $57.9 \pm 0.4 \mathrm{~mm} \mathrm{Hg}(n=3)$ and from $59.7 \pm$ 1.3 to $56.0 \pm 0.9 \mathrm{~mm} \mathrm{Hg}(n=4)$ for the 0.5 - and $1.0-\mathrm{nmol}$ doses, respectively. Of interest was that these decreases in perfusion pressure were also associated with a negative inotropic effect.

\section{DISCUSSION}

In the present study, we observed coronary vasodilatation in response to NO and to ADP, ATP, BK, and sub $\mathrm{P}$ in neonatal pig hearts, which is consistent with smooth muscle that is re- 
sponsive and an endothelium that is functionally intact and developed. This study also demonstrated that exogenously administered ACh produced dose-dependent coronary vasoconstriction. This vasoconstriction was abolished by atropine, and thus is muscarinic receptor mediated. In support of our findings, recent studies have shown that $\mathrm{ACh}$ contracts large coronary arteries isolated from adult pigs (5) and humans (6). The mechanism by which $\mathrm{ACh}$ causes this vasoconstriction, however, has not been delineated. Graser et al. (20) have suggested that the vasoconstriction produced by $\mathrm{ACh}$ in the left circumflex coronary artery of the pig does not require the presence of an intact endothelium. Similarly, Toda (21) has demonstrated an endothelium-independent, ACh-induced contraction of human coronary artery preparations. These experiments suggest that $\mathrm{ACh}$ may cross the endothelium to act directly on muscarinic receptors on the vascular smooth muscle. In contrast, Myers et al. (22) have shown that an ACh-induced contraction in large coronary arteries of pigs is augmented by agents that inactivate or inhibit the synthesis of EDRF. However, Myers et al. (22) and Christie et al. (23) found no evidence for ACh-stimulated EDRF release, although EDRF was not actually measured. These investigations would suggest that EDRF was only involved in the regulation of basal coronary artery tone. Therefore, it appears that the coronary vasoconstrictor response to $\mathrm{ACh}$ may not only involve a direct influence of $\mathrm{ACh}$ on vascular smooth muscle, but may also be opposed by an EDRF-induced vasodilatation.

In the functioning, neonatal pig heart, we found that indomethacin $\left(10^{-6} \mathrm{M}\right)$ attenuated the coronary vasoconstrictor response to $\mathrm{ACh}$ by between $48 \%$ and $87 \%$, suggesting that cyclooxygenase product release may at least partially mediate this response. Thromboxane $\mathrm{A}_{2}$ or prostaglandin endoperoxide could be involved in the vasoconstrictor process (24), inasmuch as Wagerle and Busija (25) have shown recently that these prostanoids play an important role in cerebrovascular constrictor responses to ACh in piglets. Moreover, Myers et al. (22) have shown that ACh's vasoconstriction in isolated, epicardial coronary arteries of the pig is, in part, mediated by a cyclooxygenase product, inasmuch as the vasoconstriction is attenuated by indomethacin. Our results are consistent with these findings, although our whole heart preparation does not allow us to distinguish which coronary artery segments may be more or less responsive to the effects of indomethacin. Furthermore, to demonstrate whether the vasoconstrictor response to ACh (or the inhibition of this constriction by indomethacin) depends upon an intact endothelium, responses to $\mathrm{ACh}$ would have to be studied in piglet hearts that have undergone disruption of the endothelium, e.g. by perfusing hearts with saponin (26). These experiments are beyond the scope of the present investigation.

Our study also showed that the dihydropyridine calcium antagonist, nisoldipine, attenuated the coronary vasoconstrictor response to $\mathrm{ACh}$, indicating that calcium influx from the extracellular space was involved in the smooth muscle contractile process. Endothelium-dependent contracting factors have been described that are cyclooxygenase products and that exert their effects through transsarcolemmal calcium influx (27). Therefore, one cannot exclude the possibility that the coronary vasoconstrictor response to $\mathrm{ACh}$, in these neonatal pig hearts, may involve the release of an endothelium-derived contracting factor.

$\mathrm{ACh}$ was also found to produce a dose-dependent negative inotropic effect in neonatal pig hearts that was also muscarinic receptor mediated. $\mathrm{ACh}$ is known to have negative inotropic effects in atria (28); however, the action of ACh in ventricular myocardium has not been well characterized. McIvor et al. (29) and Boyett et al. (30) have shown that ACh reduces developed tension in adult ferret papillary muscle. These investigators have suggested that the negative inotropic effect of $\mathrm{ACh}$ is a consequence of a shortening of the action potential duration, which results in a decrease in calcium influx. To our knowledge, ACh's effect on action potential duration has not been examined in neonatal hearts.
The coronary vasoconstriction produced by ACh could conceivably contribute to the negative inotropic effect. Our hearts were perfused at constant coronary flow, and thus it is unlikely that vasoconstriction impaired myocardial oxygen delivery. Nevertheless, coronary vasoconstriction to $\mathrm{ACh}$ may be heterogenous $(6,21)$, e.g. in regard to responses in epicardial versus endocardial vessels. Such an effect could result in redistribution of flow and in regions of myocardial underperfusion, and, thus, impaired mechanical function. The slight coronary vasodilatation observed during washout of ACh (Fig. 4) may reflect a release of local metabolites associated with regional underperfusion. Coronary vasoconstriction, however, cannot be a major determinant of the negative inotropic response, because $\mathrm{ACh}$ continued to cause a significant decrease in peak systolic pressure, even at lower doses (e.g. $0.1 \mathrm{nmol}$ ), for which we observed either no effect on perfusion pressure (data not shown) or a reduction in perfusion pressure (see Results). Additionally, preconstriction of the coronary vasculature, with a bolus of U46619, to a level comparable to that produced by the $5-\mathrm{nmol}$ dose of $\mathrm{ACh}$ resulted in only a minimal decrease in peak systolic pressure. It is plausible, however, that a cyclooxygenase product may have participated in the negative inotropic effect, because the decrease in left ventricular PSP produced by ACh was attenuated (by $\approx 18 \%$ ) in the presence of indomethacin. Although our study demonstrated that systolic pressure development was significantly reduced by $\mathrm{ACh}$, it is not known whether the parasympathetic innervation is sufficiently developed in neonatal hearts for the negative inotropic effect to be physiologically important.

Feigl et al. (31) studied ACh in in vivo hearts from several species by perfusing large coronary arteries at constant coronary perfusion pressure, rather than constant flow. These investigators suggested that the coronary vasoconstrictor response to ACh may indirectly result from the production of local metabolites, secondary to ACh's negative inotropic effect; however, the pig was not studied. In several experiments, we deflated the balloon to unload the left ventricle and thus decrease myocardial oxygen demands, which should have altered the production of metabolites. We found no significant change in the vasoconstrictor response to $\mathrm{ACh}$ under these conditions. Therefore, we believe it is unlikely that alterations in myocardial metabolism from impaired left ventricular pressure development contributed significantly to the dramatic increases in coronary perfusion pressure that we observed in these piglet hearts in response to $\mathrm{ACh}$.

Our data indicate that $\mathrm{ACh}$ can cause a weak coronary vasodilation at low doses $(<1.0 \mathrm{nmol})$. Similarly, Corr et al. (32) found that $\mathrm{ACh}$, at low concentrations $\left(10^{-6} \mathrm{M}\right)$, could produce relaxation of isolated rabbit epicardial coronary arteries, whereas at higher concentrations $\left(>10^{-6} \mathrm{M}\right)$ only vasoconstriction was observed. These results indicate that there may be more than one endothelium-derived factor or mechanism governing the effect of ACh on the coronary vasculature. Our data also suggest that the vasoconstrictor response to $\mathrm{ACh}$ was greater in hearts from older piglets. Additionally, the reduction in left ventricular PSP for these neonatal pig hearts was much greater than the negative inotropic effects produced by $\mathrm{ACh}$ in in vivo adult pig hearts (8). We speculate that these results may indicate that there are maturational changes in responses to $\mathrm{ACh}$, with the coronary vasoconstrictor effect increasing and the negative inotropic effect decreasing with age. Additional experiments will be required to confirm this hypothesis.

In conclusion, our study demonstrates that ACh primarily produces dose-dependent coronary vasoconstriction and a negative inotropic effect in isolated, neonatal pig hearts perfused at constant coronary flow with an erythrocyte-enriched solution. There is, however, supporting evidence with our preparation that $\mathrm{ACh}$ has a modest vasodilatory effect when administered at low doses. Our data also suggest that a prostanoid may mediate in part ACh's coronary vasoconstriction and that an extracellular source of calcium participates in this vasoconstriction. 


\section{REFERENCES}

1. Cassin S, Dawes GS, Mott JC, Ross BB, Stang LB 1964 The vascular resistance of the foetal and newly ventilated lung of the lamb. J Physiol (Lond) 171: $61-79$

2. Davidson D, Eldermerdash A 1990 Endothelium-derived relaxing factor: presence in pulmonary and systemic arteries of the newborn guinea pig. Pediatr Res 27:128-132

3. Furchgott RF, Zawadzki JV 1980 The obligatory role of endothelial cells in the relaxation of arterial smooth muscle by acetylcholine. Nature 288: 373-376

4. Kalsner S 1985 Cholinergic mechanisms in human coronary artery preparations: implications of species differences. J Physiol (Lond) 358:509-526

5. Nakayama K, Osol G, Halpern W 1988 Reactivity of isolated porcine coronary resistance arteries to cholinergic and adrenergic drugs and transmural pressure changes. Circ Res 62:741-748

6. Kalsner S 1989 Cholinergic constriction in the general circulation and its role in coronary artery spasm. Circ Res 65.237-257

7. Toda N, Okamura T, Shimizu I, Tatsuno Y 1985 Postmortem functional changes in coronary and cerebral arteries from humans and monkeys. Cardiovasc Res 19:707-713

8. Cowan CL, McKenzie JE 1990 Cholinergic regulation of resting coronary blood flow in domestic swine. Am J Physiol 259:H109-H115

9. Ignarro LJ, Buga RM, Byrns RE, Woods KS, Chaudhuri G 1984 Endotheliumderived relaxing factor and nitric oxide possess identical pharmacological properties as relaxants of smooth muscle. J Pharmacol Exp Ther 228: 682-690

10. Bassenge E, Busse R 1988 Endothelial modulation of coronary tone. Prog Cardiovasc Dis 30:349-380

11. Wagerle LC, Busija DW 1989 Cholinergic mechanisms in the cerebral circulation of the newborn piglet: effect of inhibitors of arachidonic acid metabolism. Circ Res 64:1030-1036

12. Ascuitto RJ, Ross-Ascuitto NT, Ramage D, McDonough KH 1990 Mechanical function and fatty acid oxidation in the neonatal pig heart with ischemia and reperfusion. J Dev Physiol 14:249-257

13. Ascuitto RJ, Ross-Ascuitto NT, Ramage D, McDonough KH 1990 Importance of fatty acid oxidation in the neonatal pig heart with hypoxia and reoxygenation. J Dev Physiol 14:291-294

14. Liedtke JA, Hughes HC, Neely JR 1975 Metabolic responses to varying restrictions to coronary blood flow in swine. Am J Physiol 228: H655-H662

15. Richard V, Tanner FC, Tschudi M, Luscher TF 1990 Different activation of L-arginine pathway by bradykinin, serotonin, and clonidine in coronary arteries. Am J Physiol 259:H1433-H1439
16. Beny J-L, Brunet PC 1988 Neither nitric oxide nor nitroglycerin accounts for all the characteristics of endothelially mediated vasodilatation of pig coronary arteries. Blood Vessels 25:308-311

17. Lefer AM, Tsao P, Aoki N, Palladino MA 1990 Mediation of cardioprotection by transforming growth factor-b. Science 249:61-64

18. Furchgott RF 1984 The role of endothelium in the responses of vascular smooth muscle to drugs. Annu Rev Pharmacol Toxicol 24:175-197

19. Fleckenstein-Grun G, Fleckenstein A 1990 Scope of vasodilatory effects of calcium antagonists. Blood Vessels 27:319-332

20. Graser T, Leisner H, Tiedt N 1986 Absence of role of endothelium in the response of isolated porcine coronary arteries to acetylcholine. Cardiovasc Res 20:299-302

21. Toda N 1983 Isolated human coronary arteries in response to vasoconstrictor substances. Am J Physiol 245:H937-H941

22. Myers PR, Banitt PF, Guerra R, Harrison DG 1991 Role of the endothelium in modulation of the acetylcholine vasoconstrictor response in porcine coronary microvessels. Circ Res 25:129-137

23. Christie M, Griffith T, Lewis M 1989 A comparison of basal and agoniststimulated release of endothelium-derived relaxing factor from different arteries. Br J Pharmacol 98:397-406

24. Moncada S, Vane JR 1979 Pharmacology and endogenous roles of prostaglandin endoperoxides, thromboxane $\mathrm{A}_{2}$, and prostacyclin. Pharmacol Rev 30 293-331

25. Wagerle LC, Busija DW 1990 Effect of thromboxane $A_{2}$ /endoperoxide antagonist SQ29548 on the contractile response to acetylcholine in newborn piglet cerebral arteries. Circ Res 66:824-831

26. Wiest E, Trach V, Dammgen J 1989 Removal of endothelial function in coronary resistance vessels by saponin. Basic Res Cardiol 84:469-478

27. Sanchez-Ferrer C, Marin J 1990 Endothelium-derived contractile factors. Gen Pharmacol 21:589-603

28. Garnier D, Nargeot J, Ojeda C, Rougier O 1978 The action of acetylcholine on background conductance in frog atrial trabeculae. J Physiol 174 381-396

29. McIvor ME, Orchard CH, Lakatta E 1985 -Adrenergic effects on twitch relaxation and the force-pCa relationship in heart muscle are dissociated by acetylcholine. Clin Res 33:521(abstr)

30. Boyett MR, Kirby MS, Orchard CH, Roberts A 1988 The negative inotropic effect of acetylcholine on ferret ventricular myocardium. J Physiol 404: 613-635

31. Feigl EO, Van Winkle DM, Miyashiro JK 1990 Cholinergic vasodilatation of coronary resistance vessels in dogs, baboons, and goats. Blood Vessels 27 94-105

32. Corr L, Burnstock G, Poole-Wilson P 1991 Responses of the rabbit epicardia coronary artery to acetylcholine and adrenoceptor agonists. Cardiovasc Res $25: 256-262$ 